\title{
Human induced pluripotent stem cell line banking for the production of rare blood type erythrocytes
}

\author{
Yu Jin Park ${ }^{1,2}$, Su-Hee Jeon ${ }^{1}$, Hyun-Kyung Kim¹', Eun Jung Suh' ${ }^{1}$, Seung Jun Choi ${ }^{1}$, Sinyoung Kim \\ and Hyun Ok Kim ${ }^{1 *}$
}

\begin{abstract}
Background: The in vitro production of mature human red blood cells (RBCs) from induced pluripotent stem cells (iPSCs) has been the focus of research to meet the high demand for blood transfusions. However, limitations like high costs and technological requirements restrict the use of RBCs produced by iPSC differentiation to specific circumstances, such as for patients with rare blood types or alloimmunized patients. In this study, we developed a detailed protocol for the generation of iPSC lines derived from peripheral blood of donors with O D-positive blood and rare blood types (D-and Jr(a-)) and subsequent erythroid differentiation.
\end{abstract}

Methods: Mononuclear cells separated from the peripheral blood of O D-positive and rare blood type donors were cultured to produce and expand erythroid progenitors and reprogrammed into iPSCs. A 31-day serum-free, xeno-free erythroid differentiation protocol was used to generate reticulocytes. The stability of iPSC lines was confirmed with chromosomal analysis and RT-PCR. Morphology and cell counts were determined by microscopy observations and flow cytometry.

Results: Cells from all donors were successfully used to generate iPSC lines, which were differentiated into erythroid precursors without any apparent chromosomal mutations. This differentiation protocol resulted in moderate erythrocyte yield per iPSC.

Conclusions: It has previously only been hypothesized that erythroid differentiation from iPSCs could be used to produce RBCs for transfusion to patients with rare blood types or who have been alloimmunized. Our results demonstrate the feasibility of producing autologous iPSC-differentiated RBCs for clinical transfusions in patients without alternative options.

Keywords: Induced pluripotent stem cell, Rare blood type, Red blood cell differentiation, Stem cell banking

\section{Background}

Since the 17th century, the transfusion of red blood cells (RBCs) has been a crucial part of modern medicine, enabling the alleviation of symptoms in patients with severe

\footnotetext{
*Correspondence: hyunok1019@yuhs.ac

1 Department of Laboratory Medicine, Yonsei University College

of Medicine, 50-1 Yonsei-ro, Seodaemun-gu, Seoul 03722, Republic of Korea

Full list of author information is available at the end of the article
}

anemia or trauma. Currently, RBCs are only available from donations by healthy volunteers, but insufficient numbers of donors and the potential for transfusiontransmitted infections remain considerable challenges in meeting the demand for blood [1-3]. Despite extensive efforts, it is not always easy to find a suitable blood component, and alternative systems capable of transporting oxygen to the body have been evaluated, including perfluorochemical-based RBC substitutes, hemoglobinbased RBC substitutes, and recombinant hemoglobin [4]. 
However, these blood substitutes result in insufficient oxygen delivery and an increased likelihood of death [5], and therefore are not promising alternatives [6].

During the past decade, enormous progress has been made in the ex vivo manufacture of human RBCs [7-11]. Hematopoietic stem cells (HSC) obtained from cord blood and bone marrow have been used to produce functional enucleated RBCs [12-16]. There have been numerous advances in the generation of safe erythroid cells and improvements in the efficiency of single hematopoietic cell acquisition by differentiation of CD34+ HSCs using cytokines and small molecules [9, 17-28]. As human HSCs are a limited resource and ethical concerns hinder the use of embryonic HSCs, the large-scale expansion of RBCs for transfusion purposes remains problematic.

Induced pluripotent stem cells (iPSCs) are an essentially infinite source of stem cells owing to their selfrenewal ability. Since the first report of these cells in 2006, human iPSCs have been derived from many cell types, including blood cells [29-32]. The original protocol, which involved the integration of transcription factor combinations into the cell genome, has been refined and now makes use of integration-free factors, which make iPSCs therapy for regenerative medicine applications safer [33]. Although the current methods for manipulating iPSCs are extremely inefficient and costly, iPSCs have certain benefits such as immortality, the lack of allogenic immune reactions, and the lack of ethical concerns on destruction of human embryos; therefore, studies of iPSC-derived RBC production are ongoing. An ideal strategy is to generate autologous RBCs using iPSCs, but the process is not feasible in clinical settings owing to the long time required for supplying the manufactured blood for transfusion and high cost of production.

Irrespective of the number of blood donors, maintaining an all-inclusive supply of transfusable blood for the broad population is challenging, particularly owing to alloimmunized individuals or those with rare blood types. Thirty blood group systems and over 300 RBC alloantigens have been identified, but most alloantibodies belong to the Rh, Kell, Duffy, Kidd, and MNS blood group systems [34]. The development of "universal" RBCs applicable to the entire population has been slow [35]. A study by the French National Registry of People with a Rare Blood Phenotype/Genotype suggested that 15 iPSC lines are sufficient to manage nearly all alloimmunized patients [36].

Blood banks have difficulty in finding suitable blood components for patients with rare blood types such as $\mathrm{Jr}(\mathrm{a}-)$ and Dphenotypes. $\mathrm{Jr}^{\mathrm{a}}$ is an extremely high-incidence antigen seen in all populations. The incidence of $\operatorname{Jr}(\mathrm{a}-)$ phenotype is only 0.03 to 0.12 percent even in Japanese population, which has been noted to have the highest frequency of $\operatorname{Jr}(\mathrm{a}-)$ individuals worldwide [37]. D-phenotypes are characterized by red blood cells not expressing RHCE protein at their plasma membrane, which leads to absence of $C, c, E$, and e antigens. Although this phenotype can be found in various populations, it is very rare with frequencies estimated at 0.001 percent in Japanese population [38]. Therefore, the use of iPSCs prepared from patients with rare blood types to obtain RBCs has been considered [39-42], but empirical evidence for the effectiveness and safety of this approach are lacking.

In this study, we constructed a registry of iPSC lines from peripheral blood samples collected from donors with the O D-positive and rare blood group phenotypes. We devised a detailed protocol for generating iPSCs from peripheral blood mononuclear cells (PB-MNCs) and differentiating them into functional RBCs.

\section{Materials and methods}

\section{Study design and cell sources}

After receiving consent from patients and donors, blood was collected from five $\mathrm{O} D$-positive donors and from two patients with rare blood types, D-and $\operatorname{Jr}(\mathrm{a}-)$. RBC antigenic phenotypes were determined by using monoclonal RBC antibody reagents (Ortho-Clinical Diagnostics, Raritan, NJ, USA). The H9 human embryonic stem cell line (WiCell, Madison, WI, USA) was used as a control. This study was approved by the Institutional Review Board of Yonsei University Severance Hospital, Seoul, Korea (IRB No. 4-2016-1158).

\section{Generation of induced pluripotent cell lines Isolation of $p b$-mncs from whole blood}

Peripheral blood (10-15 mL) was drawn into a tube containing sodium heparin anticoagulant (BD Biosciences, Oxford, UK). PB-MNCs were purified using either Ficoll-Paque Premium (GE Healthcare, Uppsala, Sweden) or Lymphoprep (Stem Cell Technologies, Oslo, Norway). Viable PB-MNCs were counted by the trypan blue exclusion method (Trypan Blue Stain 0.4\%; Gibco, Life Technologies, Carlsbad, CA, USA) [43].

\section{Expansion of erythroid progenitors}

To stimulate the growth of erythroid precursors, viable PB-MNCs were resuspended at a density of $1 \times 10^{6}$ cells $/ \mathrm{mL}$ in erythroid expansion medium, composed of basal medium and erythroid cytokines. The reagents used for cell cultures have been listed in Table 1 . The basal medium was prepared by adding $150 \mu \mathrm{g} / \mathrm{mL}$ transferrin (Sigma-Aldrich, Gillingham, UK), $50 \mu \mathrm{g} /$ $\mathrm{mL}$ insulin (Sigma-Aldrich), $90 \mathrm{ng} / \mathrm{mL}$ ferrous nitrate (Sigma-Aldrich), $160 \mu \mathrm{M}$ monothioglycerol (SigmaAldrich), and $1 \%$ penicillin-streptomycin (Gibco) in 
Table 1 List of reagents used for cell culture

\begin{tabular}{|c|c|c|c|}
\hline Materials & Abbreviations & Company & Catalogue\# \\
\hline Bone morphogenetic proteins 4 & BMP4 & Peprotech & $120-05$ \\
\hline Vascular endothelial growth factor & VEGF & Peprotech & $100-20$ \\
\hline Wnt3A & & Peprotech & $315-20$ \\
\hline Activin A & & Peprotech & 120-14E \\
\hline GSK-3 $\beta$ Inhibitor VIII & & Calbiochem & 361549 \\
\hline Fibroblast growth factor alpha & FGFa & Peprotech & 100-17A \\
\hline$\beta$-Estradiol & & Sigma-Aldrich & E2257 \\
\hline Insulin-like growth factor 2 & IGF2 & Peprotech & $100-12$ \\
\hline Thrombopoietin & TPO & Peprotech & $300-18$ \\
\hline Heparin & & StemCell Technologies & 07980 \\
\hline 3-Isobutyl-1-methylxanthine & IBMX & Sigma-Aldrich & 15879 \\
\hline StemRegenin 1 & SR1 & Cellagen Technology & C7710 \\
\hline Hydrocortisone & $\mathrm{HC}$ & Sigma-Aldrich & $\mathrm{H} 0888$ \\
\hline Stem cell factor & SCF & Peprotech & $300-07$ \\
\hline Interleukin 3 & $\mathrm{IL}-3$ & Peprotech & 200-03 \\
\hline Erythropoietin & $\mathrm{EPO}$ & Stem Cell & 02625 \\
\hline Poloxamer 188 & P188 & Sigma-Aldrich & P5556 \\
\hline Transferrin & TF & Sigma-Aldrich & T8158 \\
\hline Insulin & & Sigma-Aldrich & 13536 \\
\hline Ferric nitrate & FN & Sigma-Aldrich & F8508 \\
\hline Monothioglycerol & MTG & Sigma-Aldrich & M6145 \\
\hline Penicillin-Streptomycin & P-S & Gibco & 15140122 \\
\hline Y-27632 & & StemCell Technologies & 72392 \\
\hline $\begin{array}{l}\text { Stemline II hematopoietic stem cell expansion } \\
\text { medium }\end{array}$ & & Sigma-Aldrich & S0192 \\
\hline mTeSR1 basal medium & & StemCell technologies & 85851 \\
\hline mTeSR1 $5 \times$ Supplement & & StemCell technologies & 85852 \\
\hline AggreWell EB formation medium & & StemCell technologies & 05893 \\
\hline
\end{tabular}

Stemline II medium (Sigma-Aldrich). The erythroid expansion medium was prepared by adding $1 \mu \mathrm{M}$ hydrocortisone (Sigma-Aldrich), $100 \mu \mathrm{g} / \mathrm{mL}$ stem cell factor (Sigma-Aldrich), $6 \mathrm{IU} / \mathrm{mL}$ erythropoietin (StemCell Technologies, Vancouver, Canada), and $10 \mu \mathrm{g} / \mathrm{mL}$ interleukin 3 (Peprotech EC Ltd., London, UK) to the basal medium. If there were excess PB-MNCs, the surplus cells were frozen with either Cryostar (BioLife Solutions, Bothell, WA, USA) or mFreSR (StemCell Technologies).

MNCs $\left(1 \times 10^{7}\right)$ were suspended in $10 \mathrm{~mL}$ of erythroid expansion medium in a 25T (Nunc EasYFlask Cell Culture Flask, Cat\# 156367; Thermo Scientific, Waltham, MA, USA) flask and cultured for 3 days in a $5 \% \mathrm{CO}_{2}$ incubator at $37^{\circ} \mathrm{C}$. After 3 days, both non-adherent and adherent cells were recovered, and the cells were resuspended at a density of $1 \times 10^{6}$ cells $/ \mathrm{mL}$ in fresh erythroid expansion medium. From day 7, morphological analyses were performed daily until the population of erythroid progenitor cells accounted for more than $80 \%$ of the total PB-MNCs. When the population of erythroid progenitor cells reached $80 \%$ or higher, the cells were ready to be transfected. The erythroid enrichment step can be prolonged to obtain more erythroid progenitor cells in fresh erythroid expansion medium.

\section{Reprogramming of expanded erythroid progenitors}

Before transfection, each well in a 6-well multidish (Nunc Cell-Culture Treated Multidish, Cat\#140675; Thermo Scientific) was coated with a mixture of $14.5 \mu \mathrm{L}$ of Matrigel Matrix (Corning, Kennebunk, ME, USA) and $985.5 \mu \mathrm{L}$ of DMEM/F12 $(1 \times)\left(\right.$ Gibco) for $1 \mathrm{~h}$ at $25^{\circ} \mathrm{C}$. A total of $1 \times 10^{6}$ culture-expanded erythroid cells were centrifuged $(400 \times g, 5 \mathrm{~min})$ and resuspended in $104 \mu \mathrm{L}$ of medium $(18 \mu \mathrm{L}$ of supplement $1,82 \mu \mathrm{L}$ of nucleofector solution (both from the P3 Primary Cell 4D-Nucleofactor Kit, Lonza Amaxa), $2 \mu \mathrm{L}$ of Epi5 Episomal Reprogramming Vectors, and $2 \mu \mathrm{L}$ of Epi5 p53 and EBNA vectors (both from the Epi5 Episomal iPSC Reprogramming Kit; Life Technologies, Frederick, MD, USA) at $25{ }^{\circ} \mathrm{C}$ for $10 \mathrm{~min}$. Prepared cells were transferred to a $100-\mu \mathrm{L}$ 
Nucleocuvette Vessel (Lonza, Koln, Germany) and loaded on the 4D-Nucleofector System (Lonza). Electrotransfection under the 'CD34 cell, human cell type' program as per the manufacturer's instructions (https://bioscience .lonza.com/lonza_bs/US/en/download/product/asset 130292). After removing the cuvette, the processed cells were transferred to $6 \mathrm{~mL}$ of erythroid expansion medium, mixed well, and plated at a density of $3.3 \times 10^{5}$ cells per well (i.e., $2 \mathrm{~mL}$ of the cell suspension) on a Matrigel precoated 6-well plate.

Each well was supplemented with $1 \mathrm{~mL}$ of erythroid expansion medium on post-transfection day (PT-D) 2, and with $1 \mathrm{~mL}$ of ReproTeSR Basal Medium (Stem Cell Technologies) on PT-D3 and PT-D5. From PT-D7, complete medium changes were performed with $2 \mathrm{~mL}$ of ReproTeSR daily, and the cultures were close observed until colonies with an iPSC-like appearance were observed. Typically, iPSC-like colonies appeared after PT-D14. The colonies were manually picked based on their morphology between PT-D14 and PT-D24 under a polarizing microscope, and each colony was passaged as individual iPSC lines thereafter.

\section{Maintenance of induced pluripotent stem cells}

Human iPSC cultures were maintained on plates coated with $40 \mu \mathrm{L}$ of Vitronectin XF (Stem Cell Technologies) and $1 \mathrm{~mL}$ of CellAdhere Dilution Buffer (Stem Cell Technologies) for $1 \mathrm{~h}$ in $2 \mathrm{~mL}$ of mTESR 1 medium (mTeSR1 $5 \times$ Supplement 1:4 mTeSR1 Basal medium; Stem Cell Technologies). All cells were cultured at $37{ }^{\circ} \mathrm{C}$ in a humidified atmosphere containing $5 \% \mathrm{CO}_{2}$ and were cultured daily with mTESR1 media until reaching $80-90 \%$ confluence. The cells were typically ready for passage within 5 to 7 days. For the newly reprogrammed iPSCs (i.e., up to passage 3), colonies were mechanically passaged using a drawn-out glass Pasteur pipette to dissociate individual colonies. This method is used for passaging only desired undifferentiated iPSC colonies, and not unwanted differentiated colonies. From passage 3, iPSCs were enzymatically passaged using ReLeSR (Stem Cell Technologies). Medium was changed daily, and cells were subcultured once every 5 to 7 days.

\section{Differentiation into erythrocytes}

\section{Generation of embryoid bodies (EB) (Fig. 1)}

On differentiation day (DD) 0, EBs were formed on AggreWell 400 plates (Stem Cell Technologies) according to the manufacturer's instructions (https://cdn.stemc ell.com/media/files/manual/MA29146-Reproducib le_Uniform_Embryoid_Bodies_Using_AggreWell_Plate s.pdf). AggreWell plates were pre-treated with $2 \mathrm{~mL}$ of AggreWell Rinsing Solution to remove any bubbles lodged within the wells (centrifugation at $2000 \times g, 5 \mathrm{~min}$ ).
Single cells were derived from the monolayer culture of iPSCs by enzymatic treatment with Easy Gentle Cell Dissociation Reagent (Stem Cell). Approximately $2 \times 10^{6}$ single cells were seeded into each well of the AggreWell plate with $5 \mathrm{~mL}$ of AggreWell EB Formation Medium (Stem Cell Technologies) containing $10 \mu \mathrm{M} \mathrm{Y-27632}$ (Stem Cell Technologies). Cell aggregation was achieved by centrifugation at $100 \times \mathrm{g}$ for $3 \mathrm{~min}$.

On DD1, EBs from each well of the AggreWell plate were transferred to a 6-well multi-dish with Stemline II medium containing $5 \mathrm{ng} / \mathrm{mL}$ bone morphogenic protein 4 (BMP4), $5 \mathrm{ng} / \mathrm{mL}$ vascular endothelial growth factor (VEGF), $2.5 \mathrm{ng} / \mathrm{mL}$ Activin A, $5 \mathrm{ng} / \mathrm{mL}$ Wnt3A, and $0.5 \mu \mathrm{l} / \mathrm{ml}$ GSK3 $\beta$ inhibitor VIII. Cells were plated at $5 \times 10^{5}$ cells per well.

On DD3, a new set of cytokines was added to the existing culture volume along with $0.5 \mathrm{~mL}$ of Stemline II medium per well. Cytokines were added at a $6 \times$ concentration to supplement the entire volume such that the final concentrations in the well (assumed volume, $3 \mathrm{~mL}$ ) were $20 \mathrm{ng} / \mathrm{mL}$ BMP $4,30 \mathrm{ng} / \mathrm{mL}$ VEGF, $10 \mathrm{ng} / \mathrm{mL}$ Wnt3A, $5 \mathrm{ng} / \mathrm{mL}$ Activin A, $2 \mathrm{mM}$ GSK3 $\beta$ inhibitor VIII, $10 \mathrm{ng} / \mathrm{mL}$ acidic fibroblast growth factor (FGFa), $20 \mathrm{ng} /$ $\mathrm{mL}$ stem cell factor (SCF), and $0.4 \mathrm{ng} / \mathrm{mL} \beta$-estradiol.

\section{Differentiation towards hematopoietic stem cell lineage}

(Fig. 2)

On DD4, EBs were harvested, washed in DPBS, and dissociated using TrypLESelect $\times 10$ (Gibco, Thermo Scientific) for $10 \mathrm{~min}$ at $37{ }^{\circ} \mathrm{C}$. The cells were resuspended in fresh Stemline II medium and plated at $2 \times 10^{5}$ cells per well of a standard six-well tissue culture plate with the following factors: $20 \mathrm{ng} / \mathrm{mL} \mathrm{BMP4}, 30 \mathrm{ng} / \mathrm{mL}$ VEGF, $10 \mathrm{ng} / \mathrm{mL}$ FGFa, $30 \mathrm{ng} / \mathrm{mL} \mathrm{SCF}, 10 \mathrm{ng} / \mathrm{mL}$ insulin-like growth factor 2, $10 \mathrm{ng} / \mathrm{mL}$ thrombopoietin, $5 \mu \mathrm{g} / \mathrm{mL}$ heparin, $50 \mathrm{mM}$ isobutylmethyl xanthine, and $0.4 \mathrm{ng} / \mathrm{mL}$ $\beta$-estradiol.

On DD6, the differentiation factors from DD4 were refreshed by adding $0.5 \mathrm{~mL}$ Stemline II medium per well with a $6 \times$ concentration of cytokines and StemRegenin $(1 \mathrm{mM})$ was added. On DD8, cells were subjected to a complete medium change with DD4 factors. If the cell count was greater than $5 \times 10^{5}$ cells $/ \mathrm{mL}$, the culture was split, and the density was reset to $2 \times 10^{5}$ cells $/ \mathrm{mL}$ to support proliferation. On DD9, half of DD4 factors were added in $0.5 \mathrm{~mL}$ of Stemline II medium per well.

\section{Differentiation towards erythroid precursors and maturation}

On DD11, the cells were replated in erythroid liquid culture conditions. The cells were plated at a density of $3 \times 10^{6}$ cells per well in $3 \mathrm{~mL}$ of basal medium with the following cytokines: $1 \mu \mathrm{M} \mathrm{HC}, 100 \mathrm{ng} / \mathrm{mL} \mathrm{SCF}, 10 \mathrm{ng} /$ $\mathrm{mL} \mathrm{IL-3,} \mathrm{and} 6 \mathrm{IU} / \mathrm{mL}$ EPO. On DD14, the cells were 

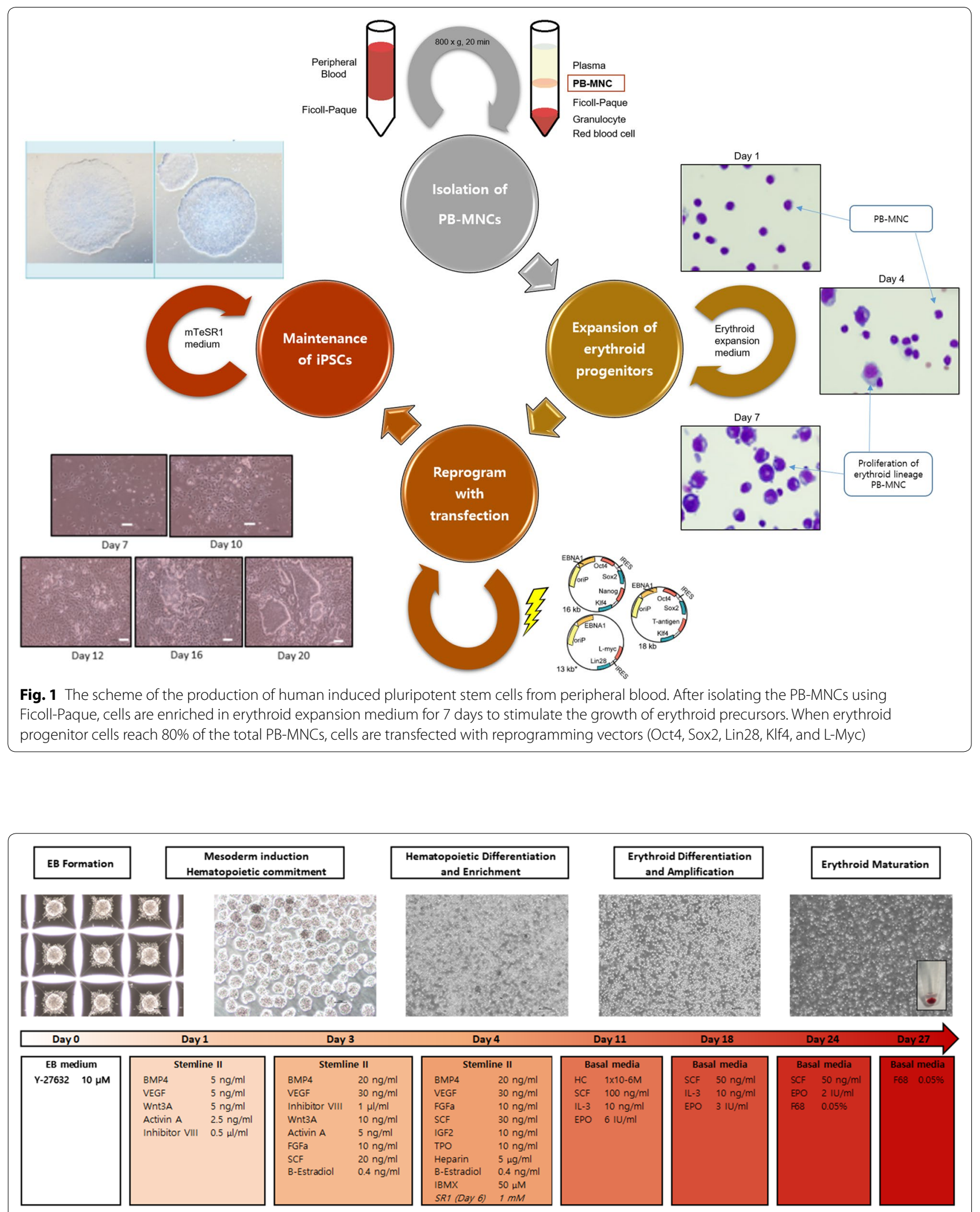

Fig. 2 Diagram representing the feeder-free and serum-free erythroid differentiation of iPSCs. Abbreviations: BMP, bone morphogenic protein; EB, embryoid body; EPO, erythropoietin; FGF, fibroblast growth factor; HC, hydrocortisone; iPSC, induced pluripotent stem cells; IBMX, isobutylmethyl xanthine; IGF, insulin-like growth factor; IL, interleukin; SCF, stem cell factor; TPO, thrombopoietin; VEGF, vascular endothelial growth factor 
subjected to a complete medium change with DD11 factors. On DD18, the cells were replated at a density of $3 \times 10^{6}$ cells per well in $3 \mathrm{~mL}$ of basal medium with the following cytokines: $50 \mathrm{ng} / \mathrm{mL} \mathrm{SCF}, 10 \mathrm{ng} / \mathrm{mL} \mathrm{IL-3,}$ and $3 \mathrm{IU} / \mathrm{mL}$ EPO. On DD21, medium was completely replaced with DD18 factors. On DD24, the cells were replated at a density of $3 \times 10^{6}$ cells per well in $3 \mathrm{~mL}$ of basal medium with the following cytokines: $50 \mathrm{ng} / \mathrm{mL}$ SCF, $2 \mathrm{IU} / \mathrm{mL}$ EPO, and $0.05 \%$ poloxamer 188 . On DD27, the cells were replated at a density of $3 \times 10^{6}$ cells per well in $3 \mathrm{~mL}$ of basal medium with $0.05 \% \mathrm{P} 188$.

\section{Detection of transfected reprogramming factor genes}

Total RNA from iPSCs was isolated using the RNeasy Plus Mini Kit (Qiagen, Hilden, Germany). Two micrograms of total RNA were used for reverse transcription reaction using the SuperScript III First Strand (Invitrogen, Thermo Scientific) according to the manufacturer's instructions. Quantitative real-time RT-PCR (qRT-PCR) was performed using qPCR TaqMan probes (Applied Biosystems) and Step One Plus (Applied Biosystems, Foster City, CA, USA). All experiments were performed in duplicate, and a non-template control (lacking the cDNA template) was included in each assay. Gene expression levels were normalized relative to levels of endogenous glyceraldehyde 3-phosphate dehydrogenase (GAPDH) and relative expression was calculated using the $\Delta \Delta C_{\mathrm{T}}$ method [44].
The following qPCR TaqMan probes (Applied Biosystems) were used: POU5F1(OCT4) Hs04260367_ gH_FAM; NANOG Hs02387400_g1_FAM; SOX2 Hs01053049_s1_FAM; KLF4 Hs00358836_m1_ FAM; c-MYC Hs00153408_m1_FAM; GAPDH Hs02758991_g1_VIC.

\section{Immunocytochemistry assay}

Reprogrammed cells were fixed in $4 \%$ paraformaldehyde (Tech \& Innovation, Gangwon-do, Korea) for $20 \mathrm{~min}$ at room temperature, washed twice with DPBS, and permeabilized with $0.2 \%$ Triton X-100 (Sigma-Aldrich) for $15 \mathrm{~min}$ at room temperature. The cells were blocked for $1 \mathrm{~h}$ with $5 \%$ donkey serum in DPBS. Samples were incubated at room temperature for $1 \mathrm{~h}$ with primary antibodies against stage-specific embryonic antigen 4 (SSEA4), octamer-binding transcription factor 4 (OCT4), sexdetermining region Y-box 2 (SOX2), TRA-1-60, and NANOG homeobox (NANOG) (all from Human Embryonic Stem Cell Marker Panel, Abcam, Cambridge, UK) (Table 2). Secondary antibodies, either Alexa Fluor 594 anti-rabbit or Alexa Fluor 488 anti-mouse antibodies (Life Technologies, Eugene, OR, USA), were incubated at room temperature for $1 \mathrm{~h}$. The nuclei were stained with 4'6-diamidino-2-phenylindole (VYSIS, Downers Grove, IL, USA). Cells were visualized under a fluorescence microscope (CKX53; Olympus, Tokyo, Japan) with an Olympus U-RFL-T fluorescence lamp. Image

Table 2 List of antibodies used for immunocytochemistry or flow cytometry

\begin{tabular}{lll}
\hline Antibodies used for immunocytochemistry & & Company, Cat\# \\
\hline Marker type & Antibody & Abcam, Cat\# ab109884 \\
\hline Embryonic stem cell markers & Rabbit anti-human OCT4 & Rabbit anti-human SOX2 \\
& Rabbit anti-human NANOG \\
& Mouse anti-human TRA-1-60 & \\
& Mouse anti-human SSEA4 & Life Technologies, Cat\# A-21207 \\
Secondary antibodies & Alexa Fluor 594 donkey anti-rabbit lgG & Life Technologies, Cat\# A-11001 \\
\hline Antibodies used for flow cytometry & Alexa Fluor 488 goat anti-mouse lgG & \\
\hline Embryonic stem cell markers & & BD Biosciences, Cat\# 560193 \\
Differentiation markers & PE mouse anti-human TRA-1-60 & BioLegend, Cat\# 330410 \\
& FITC mouse anti-human SSEA4 & BD Biosciences, Cat\# 555821 \\
& FITC mouse anti-human CD34 & BD Biosciences, Cat\# 560198 \\
& APC mouse anti-human CD43 & BD Biosciences, Cat\# 555570 \\
& PE mouse anti-human CD235a & BD Biosciences, Cat\# 551374 \\
Isotype control & APC mouse anti-human CD71 & BioLegend, Cat\# 401306 \\
& FITC mouse lgG & BD Biosciences, Cat\# 555584 \\
& PE mouse lgM & BD Biosciences, Cat\# 555751 \\
\hline
\end{tabular}


analysis and colocalization studies were performed using Ocular Image Acquisition Software (OCULAR, version 2.0.1.496; Digital Optics Limited, Auckland, New Zealand).

\section{Flow cytometric analysis}

At DD0, human iPSCs were analyzed by flow cytometry for investigating the expression of the pluripotency markers SSEA4 and TRA-1-60 (BD Biosciences). iPSCs were dissociated using Gentle Cell Dissociation Reagent (Gibco, Thermo Scientific) and aliquots of $1 \times 10^{5}$ cells/200 $\mu \mathrm{L}$ (0.5 M EDTA, pH 8.0, 1:90 DPBS) were prepared. Conjugated antibodies $\left(10 \mu \mathrm{L} / 10^{5}\right.$ cells $)$ were added to the cells and incubated on ice for $30 \mathrm{~min}$ in the dark. Unbound antibodies were removed by washing the cells with $900 \mu \mathrm{L}$ of DPBS, centrifugation at $160 \times g$ for $5 \mathrm{~min}$, and decanting the supernatant. Cells were resuspended in $400 \mu \mathrm{L}$ of $4 \%$ paraformaldehyde (Tech \& Innovation) for preservation up to 3 days.

At DD4, 11, 18, and 24, cells were analyzed by flow cytometry to evaluate their hematopoietic and erythroid characteristics. TrypleSelect $\times 10$ (Gibco, Thermo Scientific) was used to dissociate the cells, if they were not evenly dissociated. Preparation procedures were identical to those used for DD0.

All antibodies used for flow cytometry have been listed in Table 2. The BD FACSVerse Flow Cytometer (BD Biosciences) and Flowjo (version 10.2, FlowJo, LLC, Ashland, OR, USA) were used for the analysis. Nonspecific immunoglobulin isotype controls of the corresponding class served as negative controls. Compensation beads were used to modify compensation matrixes.

\section{Analysis of chromosomal abnormalities}

The cells were fixed and examined by a standard G-banding chromosome analysis [45]. The analysis was performed by GenDix, Seoul, Korea. For each cell line, 20 metaphase cells were analyzed.

\section{Morphological analysis}

Cells $\left(1 \times 10^{5}\right.$ cells per slide) were immobilized onto a glass microscope slide using a cytocentrifuge (Cytospin 4, Thermo Scientific; $800 \mathrm{rpm}, 3 \mathrm{~min}$ ) and stained with Wright-Giemsa dye (Sigma-Aldrich) for observation.

\section{Results}

\section{Establishment of iPSCs generated from PB-MNCs}

The production of hiPS cell lines from peripheral blood samples involved the following three steps: erythroblast enrichment, electrotransfection, and iPSC initiation. In the erythroblast enrichment step, the cells were transfected when the erythroblast population exceeded $80 \%$ (Fig. 3). Typically, cells were ready for transfection on day 7 of the enrichment step as the erythroblast population presenting both CD235a and CD71 antigens usually exceeded $80 \%$ by day 7 , but if the cells were not ready the enrichment step was prolonged for couple more days. When the erythroblast percentage was between $40 \%$ and $50 \%$, the enrichment step was prolonged for 2 to 3 days before transfection.

After transfection, iPSC colony isolation took 7-21 days (mean, 16 days), and individual variation was observed in colony formation efficiency with a yield of 4-10 colonies per $1 \times 10^{6} \mathrm{MNCs}$. The feeder-free transfer method was used for passaging established cell lines. The reprogramming efficiency was quite low $(0.001 \%)$, but all cultures resulted in the formation of some iPSC colonies.

\section{Characterization of the stemness of iPSCs generated using episomal vectors}

The stemness of iPSCs was verified using iPSC colonies from passages 8-10. Chromosomal analyses, qRT-PCR, flow cytometry analysis, and immunocytochemical staining of iPSCs were performed for $5 \mathrm{O}$ D-positive subjects and 2 subjects with rare blood (Fig. 4). We established that iPSCs generated from rare blood types using our protocol behave similarly in culture and colony morphologies to those of $\mathrm{H} 9$ or $\mathrm{O}$ D-positive controls. A chromosomal analysis of all peripheral blood iPSC colonies showed a normal karyotype. Quantitative RT-PCR showed expression of transfected reprogramming factor genes. By flow cytometry analysis, single cells were shown to express pluripotency markers TRA-1-60 and SSEA4. Immunocytochemistry assay revealed that iPSC clones retained the typical characteristics of pluripotent stem cells, including the expression of embryonic stem cell markers (e.g., OCT4, SOX2, NANOG, TRA-1-60, and SSEA4). These data demonstrated the pluripotency of the iPSCs.

\section{Differentiation of banked iPSCs into erythroid lineage cells} Erythroid cell morphology developed over time during the differentiation cultures (Fig. 5a). A shift from a relatively large proportion of hematopoietic precursor cells (HPCs) to differentiated erythroid precursors were observed between DD4 and DD24; during this time, the population shift was evident by flow cytometry analysis (Fig. 5b). The cumulative change in cell number from iPSCs to differentiated cells after 24 days were between 8 and 18-folds (Fig. 5c). Jr(a-) and H9 cell lines showed similar amplification curves until DD15, and then $\operatorname{Jr}(\mathrm{a}-)$ showed accelerated proliferation reaching up to 17 -folds by DD24, whereas H9 stopped at nine-folds. In contrast, D- cell line showed accelerated growth in the beginning of the differentiation protocol, and the final cumulative 

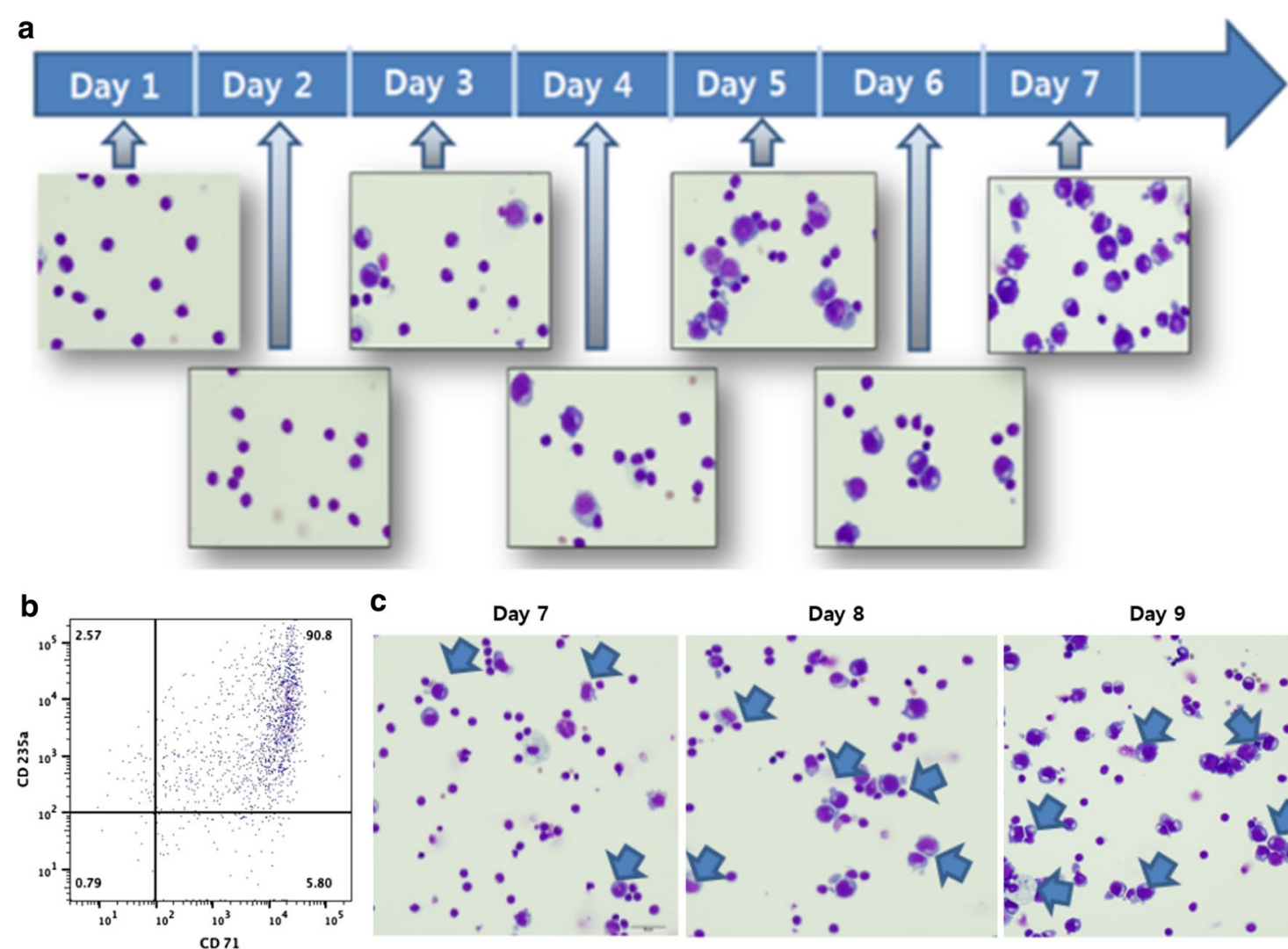

C
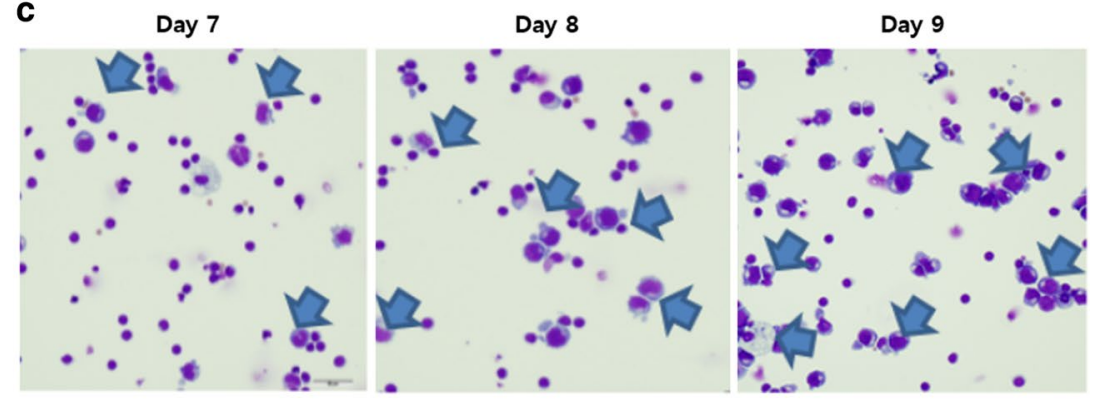

Fig. 3 Counting erthyroblast cells to determine the date for transfection: a separated PB-MNCs were enriched with cytokines adequate for promoting erythroid progenitors. Typically, erythroblast population exceeded $80 \%$ on expansion day 7 . b flow cytometry analysis of 7-days enriched erythroid progenitors presenting CD235a and CD71 antigens. c On erythroblast expansion day 7, if the observed erythroblast population (blue arrow) was less than $80 \%$, transfection was performed after extending the expansion step for 2-3 days in the same conditions

folds for rare blood groups were similar on DD24, which were higher than that of the $\mathrm{H} 9$ cell line.

Using flow cytometry, the markers of HSCs (CD34 and CD43), early erythroid progenitors (CD71), and mature erythroid cells (CD235a) were detected (Fig. 5d). Antigen presentation for each cell lines varied, but some common characteristics could be found. CD $34+$ CD $43+$ HSC population was observed in $\mathrm{H} 9$ cell lines on DD11, but CD34 antigen was not observed in any of the rare blood type cell lines. In all cell lines, early HPCs expressing CD43 were detected from DD11 onwards [46]. Most HSCs were differentiated into HPCs, whereas HPCs were observed throughout the duration of the differentiation protocol, with a decrease in CD34 and high frequency of CD43. CD71, which is selectively expressed at high levels not only in erythroid precursors but also in all proliferating cells [47], was strongly expressed in all erythroid precursors and even in HSCs. The mature erythroid cell marker, CD235a was prominently observed after DD18 and peaked on DD24, which were more readily observed in $\mathrm{H} 9$ and $\mathrm{Jr}(\mathrm{a}-)$ cell lines. Generally, the order of antigenic profile for the differentiated cells were CD71, followed by CD43 with or without presence of CD34, and finally $\mathrm{CD} 235 \mathrm{a}+\mathrm{CD} 71$ high population.

\section{Discussion}

Extensive studies have evaluated the differentiation of iPSCs into erythrocytes as a possible strategy to meet the demand for blood components [7, 8, 11]. Various protocols have been developed all of which follow the same basic steps: iPSC generation by incorporating pluripotent genetic factors, self-renewal and expansion of the iPSCs, and differentiation into erythroid lineage cells, which includes commitment, expansion, and maturation [27, 31, 48-50]. Many studies have focused on specific parts of the protocol, but relatively few studies have evaluated the entire process, starting from iPSC generation to erythroid differentiation.

Finding suitable starting population for growing RBCs has been a challenge. The main source materials to produce RBCs in vitro are hematopoietic stem/ progenitor cells, embryonic stem cells, and iPSCs [51]. 

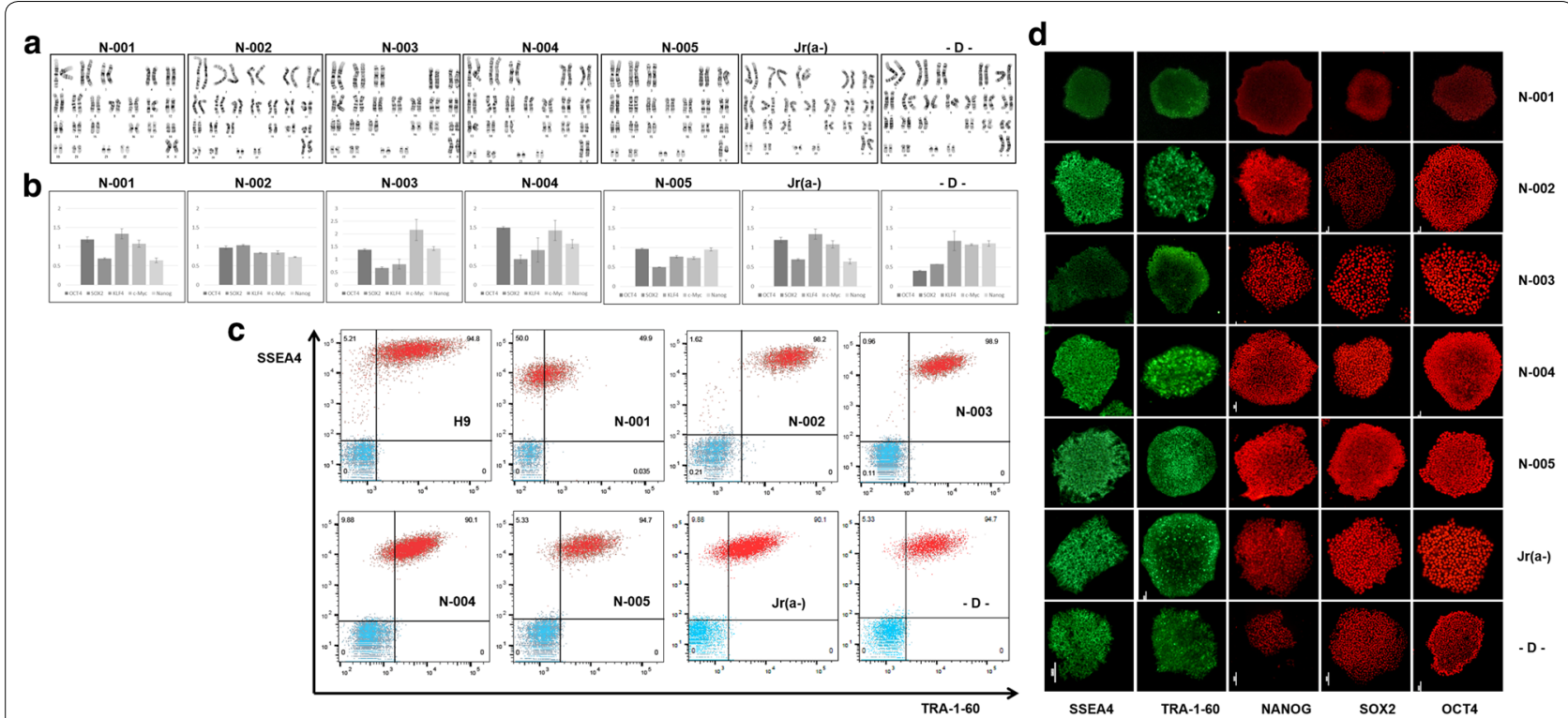

Fig. 4 Stemness characterization of iPSCs generated from normal donor (N-001 N-005) and patients with rare blood type (Jr(a-), D-): a chromosomal analysis showed normal karyotypes for all cell lines, $\mathbf{b}$ quantitative reverse transcription polymerase chain reaction revealed successful transfection of reprogramming factor genes, $\mathbf{c}$ flow cytometric analysis and $\mathbf{d}$ immunocytochemistry assay indicated that each cell line expressed embryonic stem cell markers (SSEA4, TRA-1-60, NANOG, SOX4, and OCT4)

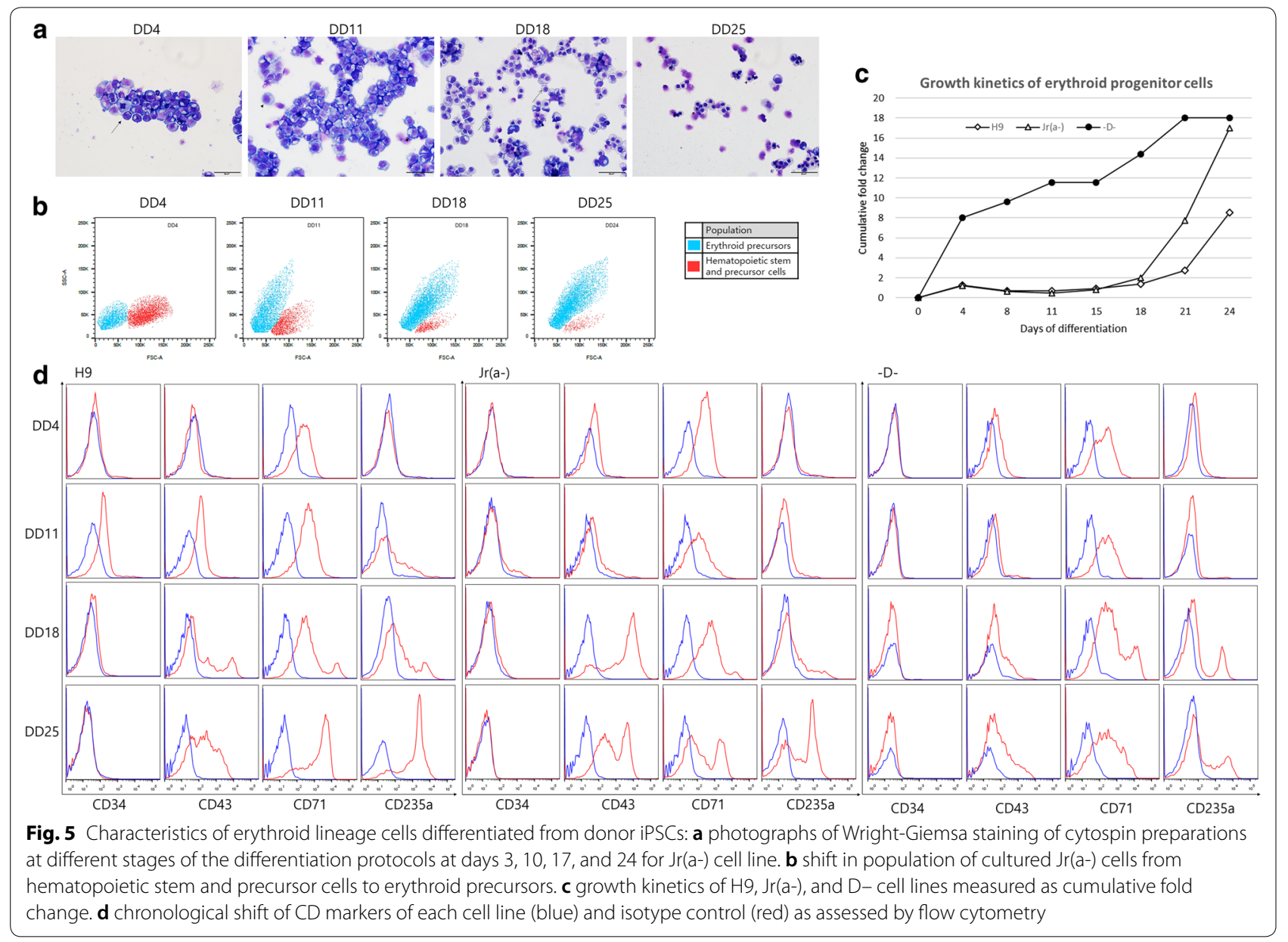


The major advantage of iPSCs over other source materials is that they can be produced from any type of cells, both immature and mature cells without causing ethical concerns arisen by using human embryos [52]. Our experiment used PB-MNCs as the starting population for iPSCs because reprogrammed iPSCs may retain epigenetic memory inherited from the parental cells. Therefore, using hematopoietic cells were preferable to other sources such as fibroblasts.

Assuming that efficient in vitro large-scale cultured $\mathrm{RBC}$ production will be possible in the near future, the banking of iPSC clones may be a key strategy for providing iPSC-derived RBCs. Based on this approach, our laboratory has started to build a registry of iPSC clones from many O D-positive and O D-negative donors. By confirming that the antigen profiles of donor RBCs match those of differentiated RBCs, we believe that it is possible to create a registry suitable for nearly $100 \%$ of the Korean population with a handful of iPSC lines. There are few exceptions where autologous transfusions are needed, such as in the case of patients with rare blood types or alloimmunized patients receiving multiple transfusions, hence separate registry including these rare patients are required.

In this study, PB-MNCs from two patients with rare blood types ( $\operatorname{Jr}(\mathrm{a}-)$ and $\left.\mathrm{D}^{-}\right)$were successfully used to generate iPSCs and differentiated into RBCs. The detailed protocol described in this research encompasses the entire process in a detailed manner, from the expansion of PB-MNCs and generation of iPSCs by transfection of episomal vectors, maintenance of iPSCs, and differentiation into erythroid lineage cells. Furthermore, this process makes use of our serum-free, xeno-free protocol which is compatible with the Good Manufacturing Practice (GMP). The use of autologous iPSC-derived RBCs from patients with rare blood types has been described in theory; however, to the best of our knowledge, this is the first report of banking rare blood type iPSCs for producing GMP-grade erythrocytes.

The major limitations for the clinical application of iPSC-derived RBCs are the inefficient RBC enucleation, difficulty of switching to adult-type globin, and the substantial number of RBCs $\left(10^{12}\right)$ needed to generate 1 unit of transfusable RBCs. Our protocol suffered from similar limitations, therefore the use of other small molecules and cytokines should be explored to overcome these hurdles [22-24]. Prior to using iPSC-derived RBCs clinically, further investigations are needed including: evaluation of RBC antigen profile, additional evaluation of iPSCs for genomic mutations, testing of the RBCs in agglutination assays, and/or safety testing of the RBCs in animal models. Lastly, in this study each cell line was differentiated into erythroid cells only once. Replicate experiments must be performed to make this protocol more robust and eliminate any variabilities.

Recently published articles deal with similar limitations and tries to find novel methods using modified cytokine mixtures and microenvironments. To produce GMP grade transfusable RBCs, many researchers are removing animal or human derived substances from prior protocols $[53,54]$. Although it may be more costly and inefficient so far, xeno- and feeder-free methods are necessary to reduce possible side effects of manufactured RBCs when transfused to patients. Use of bioreactors, modifying microenvironments using macrophages and small molecules, and utilizing genetic alterations are currently being developed to enhance survival of mature RBCs, increase enucleation rate, and promote hemoglobin switching [54-57].

\section{Conclusions}

In conclusion, our findings demonstrate the feasibility of building a registry of iPSC clones from O D-positive donors and patients with rare blood types using a carefully developed serum-free, xeno-free protocol. The development of banked iPSCs for both research and clinical applications is an important step in the advancement of personalized medicine, and in fulfilling the need to establish specialized stem cell registry dedicated to RBC transfusions.

\section{Abbreviations}

BMP4: Bone morphogenic protein 4; DD: Differentiation day; EB: Embryoid bodies; FGFa: Acidic fibroblast growth factor; GMP: Good Manufactory Practice; HPCs: Hematopoietic precursor cells; HSC: Hematopoietic stem cells; iPSC: Immortalized induced pluripotent stem cell; NANOG: NANOG homeobox; OCT4: Octamer-binding transcription factor 4; PB-MNCs: Peripheral blood mononuclear cells; PT-D: Post-transfection day; qRT-PCR: Quantitative realtime RT-PCR; RBC: Red blood cells; SCF: Stem cell factor; SSEA4: Stage-specific embryonic antigen 4; SOX2: Sex-determining region Y-box 2; VEGF: Vascular endothelial growth factor.

\section{Acknowledgements \\ None.}

\section{Authors' contributions}

YJP performed study, analysis, and wrote manuscript. SHJ, HKK, and EJS participated in cell cultures and experiments. SJC and SK contributed discussion and edited manuscript. HOK provided funding support, designed study and reviewed manuscript. All authors read and approved the final manuscript.

\section{Funding}

This study was supported by a Severance Hospital Research fund for Clinical excellence (SHRC) (C-2019-0034).

\section{Availability of data and materials \\ The datasets used and analyzed during the current study are available from the corresponding author on reasonable request.}

Ethics approval and consent to participate

This study was approved by the Institutional Review Board of Yonsei University Severance Hospital, Seoul, Korea (IRB No. 4-2016-1158). All participants read 
and signed an informed consent document with the description of the testing procedures.

\section{Consent for publication}

Not applicable.

\section{Competing interests}

The authors declare that they have no competing interests.

\section{Author details}

1 Department of Laboratory Medicine, Yonsei University College of Medicine, 50-1 Yonsei-ro, Seodaemun-gu, Seoul 03722, Republic of Korea. ${ }^{2}$ Department of Laboratory Medicine, Armed Forces Yangju Hospital, Yangju-si, Gyeonggi-do, Korea.

Received: 9 April 2020 Accepted: 4 June 2020

Published online: 12 June 2020

\section{References}

1. Roberts DJ, Field S, Delaney M, Bates I. Problems and approaches for blood transfusion in the developing countries. Hematol Oncol Clin North Am. 2016:30(2):477-95.

2. Greinacher A, Fendrich K, Brzenska R, Kiefel V, Hoffmann W. Implications of demographics on future blood supply: a population-based crosssectional study. Transfusion. 2011;51(4):702-9.

3. Williamson LM, Devine DV. Challenges in the management of the blood supply. Lancet. 2013;381(9880):1866-75

4. Keyhanian S, Ebrahimifard M, Zandi M. Investigation on artificial blood or substitute blood replace the natural blood. Iran J Ped Hematol Oncol. 2014;4(2):72-7.

5. Natanson C, Kern SJ, Lurie P, Banks SM, Wolfe SM. Cell-free hemoglobinbased blood substitutes and risk of myocardial infarction and death: a meta-analysis. JAMA. 2008;299(19):2304-12.

6. Alayash Al. Blood substitutes: why haven't we been more successful? Trends Biotechnol. 2014;32(4):177-85.

7. Batta K, Menegatti S, Garcia-Alegria E, Florkowska M, Lacaud G, Kouskoff $\checkmark$. Concise review: recent advances in the in vitro derivation of blood cell populations. Stem Cells Transl Med. 2016;5(10):1330-7.

8. Easterbrook J, Fidanza A, Forrester LM. Concise review: programming human pluripotent stem cells into blood. Br J Haematol. 2016;173(5):671-9.

9. Giarratana MC, Kobari L, Lapillonne H, Chalmers D, Kiger L, Cynober T, et al. Ex vivo generation of fully mature human red blood cells from hematopoietic stem cells. Nat Biotechnol. 2005;23(1):69-74.

10. Paes B, Moco PD, Pereira CG, Porto GS, de Sousa Russo EM, Reis LCJ, et al. Ten years of iPSC: clinical potential and advances in vitro hematopoietic differentiation. Cell Biol Toxicol. 2017;33(3):233-50.

11. Shah S, Huang $X$, Cheng L. Concise review: stem cell-based approaches to red blood cell production for transfusion. Stem Cells Transl Med. 2014;3(3):346-55.

12. Baek EJ, Kim HS, Kim S, Jin H, Choi TY, Kim HO. In vitro clinical-grade generation of red blood cells from human umbilical cord blood CD34+ cells. Transfusion. 2008;48(10):2235-45

13. Cantu I, Philipsen S. Flicking the switch: adult hemoglobin expression in erythroid cells derived from cord blood and human induced pluripotent stem cells. Haematologica. 2014;99(11):1647-9.

14. Kovilakath A, Mohamad S, Hermes F, Wang SZ, Ginder GD, Lloyd JA. In vitro erythroid differentiation and lentiviral knockdown in human CD34+ cells from umbilical cord blood. Methods Mol Biol. 2018;1698:259-74.

15. Merryweather-Clarke AT, Tipping AJ, Lamikanra AA, Fa R, Abu-Jamous $B$, Tsang HP, et al. Distinct gene expression program dynamics during erythropoiesis from human induced pluripotent stem cells compared with adult and cord blood progenitors. BMC Genomics. 2016;17(1):817.

16. Vinjamur DS, Bauer DE. Growing and genetically manipulating Human Umbilical Cord Blood-Derived Erythroid Progenitor (HUDEP) cell lines. Methods Mol Biol. 2018;1698:275-84.
17. Baek EJ, Kim HS, Kim JH, Kim NJ, Kim HO. Stroma-free mass production of clinical-grade red blood cells (RBCs) by using poloxamer 188 as an RBC survival enhancer. Transfusion. 2009;49(11):2285-95.

18. Dias J, Gumenyuk M, Kang H, Vodyanik M, Yu J, Thomson JA, et al. Generation of red blood cells from human induced pluripotent stem cells. Stem Cells Dev. 2011;20(9):1639-47.

19. Ganji F, Abroun S, Baharvand H, Aghdami N, Ebrahimi M. Differentiation potential of o bombay human-induced pluripotent stem cells and human embryonic stem cells into fetal erythroid-like cells. Cell J. 2015;16(4):426-39.

20. Huang $X$, Wang Y, Yan W, Smith C, Ye Z, Wang J, et al. Production of genecorrected adult beta globin protein in human erythrocytes differentiated from patient iPSCs after genome editing of the sickle point mutation. Stem Cells. 2015;33(5):1470-9.

21. Kim SJ, Jung JW, Ha HY, Koo SK, Kim EG, Kim JH. Generation of hematopoietic stem cells from human embryonic stem cells using a defined, stepwise, serum-free, and serum replacement-free monolayer culture method. Blood Res. 2017;52(1):37-43.

22. Olivier EN, Marenah L, McCahill A, Condie A, Cowan S, Mountford JC. High-efficiency serum-free feeder-free erythroid differentiation of human pluripotent stem cells using small molecules. Stem Cells Transl Med. 2016;5(10):1394-405

23. Sivalingam J, Chen HY, Yang BX, Lim ZR, Lam ATL, Woo TL, et al. Improved erythroid differentiation of multiple human pluripotent stem cell lines in microcarrier culture by modulation of Wnt/beta-Catenin signaling. Haematologica. 2018;103(7):e279-83.

24. Sivalingam J, Lam AT, Chen HY, Yang BX, Chen AK, Reuveny S, et al. Superior red blood cell generation from human pluripotent stem cells through a novel microcarrier-based embryoid body platform. Tissue Eng Part C Methods. 2016;22(8):765-80.

25. Verma R, Su S, McCrann DJ, Green JM, Leu K, Young PR, et al. RHEX, a novel regulator of human erythroid progenitor cell expansion and erythroblast development. J Exp Med. 2014;211(9):1715-22.

26. Wang Y, Chou BK, Dowey S, He C, Gerecht S, Cheng L. Scalable expansion of human induced pluripotent stem cells in the defined xeno-free E8 medium under adherent and suspension culture conditions. Stem Cell Res. 2013;11(3):1103-16.

27. Wang Y, Gao Y, He C, Ye Z, Gerecht S, Cheng L. Scalable production of human erythrocytes from induced pluripotent stem cells. bioRxiv. 2016. https://doi.org/10.1101/050021.

28. Yang CT, Ma R, Axton RA, Jackson M, Taylor AH, Fidanza A, et al. Activation of KLF1 enhances the differentiation and maturation of red blood cells from human pluripotent stem cells. Stem Cells. 2017;35(4):886-97.

29. Dowey SN, Huang X, Chou BK, Ye Z, Cheng L. Generation of integration-free human induced pluripotent stem cells from postnatal blood mononuclear cells by plasmid vector expression. Nat Protoc 2012;7(11):2013-21.

30. Gu H, Huang X, Xu J, Song L, Liu S, Zhang XB, et al. Optimizing the method for generation of integration-free induced pluripotent stem cells from human peripheral blood. Stem Cell Res Ther. 2018;9(1):163.

31. Kim Y, Rim YA, Yi H, Park N, Park SH, Ju JH. The generation of human induced pluripotent stem cells from blood cells: an efficient protocol using serial plating of reprogrammed cells by centrifugation. Stem Cells Int. 2016. https://doi.org/10.1155/2016/1329459.1329459.

32. Quintana-Bustamante O, Segovia JC. Generation of patient-specific induced pluripotent stem cell from peripheral blood mononuclear cells by sendai reprogramming vectors. Methods Mol Biol. 2016;1353:1-11.

33. Hubbard JJ, Sullivan SK, Mills JA, Hayes BJ, Torok-Storb BJ, Ramakrishnan A. Efficient iPS cell generation from blood using episomes and HDAC inhibitors. J Vis Exp. 2014;92:e52009. https://doi.org/10.3791/52009.

34. Mitra R, Mishra N, Rath GP. Blood groups systems. Indian J Anaesth. 2014;58(5):524-8

35. Kwan DH, Constantinescu I, Chapanian R, Higgins MA, Kotzler MP, Samain $\mathrm{E}$, et al. Toward efficient enzymes for the generation of universal blood through structure-guided directed evolution. J Am Chem Soc. 2015;137(17):5695-705.

36. Peyrard T, Bardiaux L, Krause C, Kobari L, Lapillonne H, Andreu G, et al. Banking of pluripotent adult stem cells as an unlimited source for red blood cell production: potential applications for alloimmunized patients and rare blood challenges. Transfus Med Rev. 2011;25(3):206-16. 
37. Nakajima H, Ito K. An example of anti-Jra causing hemolytic disease of the newborn and frequency of Jra antigen in the Japanese population. Vox Sang. 1978;35(4):265-7.

38. Daniels G. Human blood groups. Oxford: Blackwell Science Ltd.; 1995.

39. Focosi D, Pistello M. Effect of induced pluripotent stem cell technology in blood banking. Stem Cells Transl Med. 2016;5(3):269-74.

40. Al-Anazi KA. Induced pluripotent stem cells and their future therapeutic applications in hematology. J Stem Cell Res Ther. 2015;5:258.

41. Focosi D, Amabile G, Di Ruscio A, Quaranta P, Tenen DG, Pistello M Induced pluripotent stem cells in hematology: current and future applications. Blood Cancer J. 2014;4:e211.

42. Burger P, Eernstmans J, Hansen M, Ovchynnikova E, Wüst T, ThijssenTimmer D, et al. From induced pluripotent stem cells to massive erythroid expansion: a glimpse into the future of transfusion medicine. Cytotherapy. 2015;17(6):S7-8.

43. Strober W. Trypan blue exclusion test of cell viability. Curr Protoc Immunol. 2015;111:A3-B.

44. Schmittgen TD, Livak KJ. Analyzing real-time PCR data by the comparative C(T) method. Nat Protoc. 2008;3(6):1101-8.

45. Howe B, Umrigar A, Tsien F. Chromosome preparation from cultured cells. J Vis Exp JoVE. 2014;83:e50203-e. https://doi.org/10.3791/50203.

46. Vodyanik MA, Thomson JA, Slukvin II. Leukosialin (CD43) defines hematopoietic progenitors in human embryonic stem cell differentiation cultures. Blood. 2006;108(6):2095-105.

47. Li J, Hale J, Bhagia P, Xue F, Chen L, Jaffray J, et al. Isolation and transcriptome analyses of human erythroid progenitors: bFU-E and CFU-E. Blood. 2014;124(24):3636-45.

48. Trakarnsanga K, Griffiths RE, Wilson MC, Blair A, Satchwell TJ, Meinders M, et al. An immortalized adult human erythroid line facilitates sustainable and scalable generation of functional red cells. Nat Commun. 2017:8:14750.

49. Uchida N, Demirci S, Haro-Mora JJ, Fujita A, Raines LN, Hsieh MM, et al. Serum-free erythroid differentiation for efficient genetic modification and high-level adult hemoglobin production. Mol Ther Methods Clin Dev. 2018:9:247-56.
50. Rao MS, Pei Y, Garcia TY, Chew S, Kasai T, Hisai T, et al. Illustrating the potency of current Good Manufacturing Practice-compliant induced pluripotent stem cell lines as a source of multiple cell lineages using standardized protocols. Cytotherapy. 2018;20(6):861-72.

51. Colligan D, McGowan N, Seghatchian J. Optimal use of blood and innovative approaches to stem cells, regenerative medicine and donor recruitment. Transfus Apher Sci. 2014;50(2):303-6.

52. Noguchi H, Miyagi-Shiohira C, Nakashima Y. Induced tissue-specific stem cells and epigenetic memory in induced pluripotent stem cells. Int J Mol Sci. 2018;19(4):930.

53. Bernecker C, Ackermann M, Lachmann N, Rohrhofer L, Zaehres H, AraúzoBravo MJ, et al. Enhanced ex vivo generation of erythroid cells from human induced pluripotent stem cells in a simplified cell culture system with low cytokine support. Stem Cells Dev. 2019;28(23):1540-51.

54. Olivier EN, Zhang S, Yan Z, Suzuka S, Roberts K, Wang K, et al. PSC-RED and MNC-RED: albumin-free and low-transferrin robust erythroid differentiation protocols to produce human enucleated red blood cells. Exp Hematol. 2019;75(31-52):e15.

55. Lopez-Yrigoyen M, Yang CT, Fidanza A, Cassetta L, Taylor AH, McCahill A, et al. Genetic programming of macrophages generates an in vitro model for the human erythroid island niche. Nat Commun. 2019;10(1):881.

56. Nakagawa Y, Nakamura S, Nakajima M, Endo H, Dohda T, Takayama N, et al. Two differential flows in a bioreactor promoted platelet generation from human pluripotent stem cell-derived megakaryocytes. Exp Hematol. 2013;41(8):742-8.

57. Christaki EE, Politou M, Antonelou M, Athanasopoulos A, Simantirakis E, Seghatchian J, et al. Ex vivo generation of transfusable red blood cells from various stem cell sources: a concise revisit of where we are now. Transfus Apher Sci. 2019;58(1):108-12.

\section{Publisher's Note}

Springer Nature remains neutral with regard to jurisdictional claims in published maps and institutional affiliations.
Ready to submit your research? Choose BMC and benefit from:

- fast, convenient online submission

- thorough peer review by experienced researchers in your field

- rapid publication on acceptance

- support for research data, including large and complex data types

- gold Open Access which fosters wider collaboration and increased citations

- maximum visibility for your research: over 100M website views per year

At BMC, research is always in progress.

Learn more biomedcentral.com/submissions 